\title{
A study to determine the knowledge and level of awareness of medical undergraduates about herbal medicines and herb-drug interactions
}

\author{
Jaspreet K. Boparai ${ }^{1}$, Amandeep Singh ${ }^{2} *$, Ashwani K. Gupta ${ }^{3}$, Prithpal S. Matreja ${ }^{4}$, \\ P. M. L. Khanna ${ }^{5}$, Vipan Gupta ${ }^{6}$, Rakesh K. Gautam ${ }^{7}$
}

\begin{abstract}
${ }^{1}$ Department of Pharmacology, Gian Sagar Medical College and Hospital, Rajpura, Punjab 140601, India

${ }^{2}$ Department of Pharmacology, Shri Guru Ram Rai Institute of Medical and Health Sciences, Patel Nagar, Dehradun, Uttarakhand 248001, India

${ }^{3}$ Department of Pharmacology, Maharishi Markendeshwar Institute of Medical Science and Research, Mullana, Ambala, Haryana 133207, India

${ }^{4}$ Department of Pharmacology, Teerthanker Mahaveer Medical College and Research Center, Delhi Road, Moradabad, Uttar Pradesh 244001, India

${ }^{5}$ Department of Pharmacology, Gian Sagar Medical College and Hospital, Rajpura, Punjab 140601, India

${ }^{6}$ Department of

Otorhinolaryngology, Maharishi Markandeshwar Institute of Medical Science and Research, Solan, Himachal Pradesh 173229, India ${ }^{7}$ Department of Orthopedics, Maharishi Markendeshwar Institute of Medical Science \& Research, Mullana, Ambala, Haryana 133207, India
\end{abstract}

Received: 05 December 2016

Revised: 08 December 2016

Accepted: 10 December 2016

*Correspondence to:

Dr. Amandeep Singh,

Email: angad.aman@gmail.com

Copyright: (c) the author(s), publisher and licensee Medip Academy. This is an open-access article distributed under the terms of the Creative Commons Attribution Non-Commercial License, which permits unrestricted noncommercial use, distribution, and reproduction in any medium, provided the original work is properly cited.

\begin{abstract}
Background: The increasing usage of herbal medicines worldwide has increased the probability of co-administration of herbal and allopathic medicines. This may lead to serious safety concerns, including herb-drug interactions (HDIs). Many HDIs may be overlooked due to poor doctor-patient communication about herbal drug usage probably because of lack of knowledge of herbal medicines and HDIs among physicians. The study was thus planned to identify the knowledge and awareness of medical students regarding the use of herbal medicines and about HDIs, to help improve the teaching skills and curriculum development for medical students.

Methods: 286 medical students of $2^{\text {nd }}, 3^{\text {rd }}$ and $4^{\text {th }}$ year MBBS course completed the study. All the participants were asked to fill a self-administered questionnaire consisting of 15 questions which included both open-ended and close-ended questions related to age, sex, knowledge, awareness and usage of herbal medicines and about herb-drug interactions. Data was analyzed and expressed as counts and percentages.

Results: Majority $(95.45 \%)$ of the students were aware of the fact that herbs can be used as medicines. They were most familiar with the herbs tulsi, neem, turmeric, aloe, ashwagandha and ginger. $46.85 \%$ consider herbal medicines to be risk free, and majority (55.6\%) were not aware of the fact that herbs can cause herb-drug interactions. Media and elderly family members were their most common sources of information regarding herbal medicines. Majority $(75.17 \%)$ would prefer allopathic medicines over herbal medicines. Only $23.07 \%$ always informed the physician about their usage of herbal medicines, although most $(84.96 \%)$ felt that history regarding use of herbal medicines should be taken. Majority were not aware of the regulatory status of herbal medicines.

Conclusions: Lack of knowledge and awareness of medical students about herbal medicines and herb-drug interactions was seen in the study. There is a need to inform the students of allopathic system of medicine about the adverse outcomes of herbal medicines and the knowledge about herb-drug interactions should be a part of the medical curriculum.
\end{abstract}

Keywords: Allopathic medicine, Herbal medicines, Herb-drug interactions, Medical curriculum, Pharmacology practical 


\section{INTRODUCTION}

Herbal medicines include herbs, herbal materials, preparations and products that contain parts of plants or other plant materials as active ingredients. ${ }^{1}$ According to World health organization (WHO), 80\% of the world population is dependent on traditional medicines (mainly herbal medicines) for their primary health care needs. In European union, the use is as high as up to $90 \%$ of the population in some countries. ${ }^{2}$ In India also, herbal drugs are used by around $70 \%$ of the population. ${ }^{3}$ Herbs commonly used worldwide include St. Johns wort, ginkgo biloba, kava-kava, ginseng and garlic. ${ }^{4}$

The general belief that herbal drugs being natural are safe; increasing dependence of people on dietary supplements; and the low cost of some herbal drugs have led to the extensive use of herbal medicines worldwide. ${ }^{5}$ Herbal drugs are often self-prescribed and are freely available over-the-counter. ${ }^{6}$ Herbs are however not free from side effects, and some have been shown to be toxic. $^{7,8}$

All this may lead to serious safety concerns with usage of herbal medicines, including herb-drug interactions (HDIs); the increasing evidence of which are being documented nowadays. ${ }^{4,9}$ In a study by Gohil et al, St. Johns wort was among the commonest herb involved in HDIs, followed by ginkgo biloba, kava-kava, ginger and ginseng. ${ }^{10}$ As per a systematic review by Posadzki $\mathrm{P}$ et al, the most common HDIs were with antiplatelet agents and anticoagulants. ${ }^{11}$ Use of ginger, garlic, ginkgo, ginseng with anti-platelets may cause bleeding; St. Johns wort may decrease the effectiveness of digoxin, oral contraceptives, warfarin, clopidogrel; and ginkgo may interact with a number of drugs including benzodiazepines, atorvastatin, anticonvulsant drugs., ${ }^{4,10}$ The HDIs may even result in severe interactions including transplant rejection, cardiovascular collapse, renal toxicity, liver toxicity, cardiotoxicity, organ fibrosis and death. $^{11}$

Various studies have shown that most patients do not consider it necessary to disclose about their herbal medicine intake to physicians. ${ }^{12,13}$ In two different survey-based studies, nearly $70 \%$ of patients who took a herbal medicine with allopathic medicines, did not inform their physician about herbal drug consumption. ${ }^{14,15}$ This is supported by the facts that many physicians themselves rarely ask their patients about herbal medicine consumption, and many are unaware of the potential risks of herb-drug interactions. ${ }^{12,13,15,16}$ Prescribers of modern allopathic medicine often have little or no training of the effects of herbal medicines on humans and their potential to cause HDIs. ${ }^{17,18,19}$ Thus, the chances of suspecting HDIs become very less. The education and training of healthcare providers regarding herb-drug interactions is thus essential for safe and rational drug therapy.
This study was thus planned to know the knowledge and awareness of medical students regarding the use of herbal medicines and about herb-drug interactions. This would help to improve the teaching skills and curriculum development for students of allopathic system of medicine.

\section{METHODS}

This cross-sectional study was conducted in the department of pharmacology, Gian Sagar Medical College and Hospital, Patiala from July to December, 2013. The study was approved by Institutional Ethics Committee of the institute. A total of 300 medical MBBS students of $2^{\text {nd }}, 3^{\text {rd }}$ and final year were enrolled in the study after informed consent was obtained from all the participants. The student's participation was completely voluntary without revealing their identity in the questionnaire. All the participants were asked to fill a self-administered questionnaire consisting of 15 questions which included both open ended and close ended (multiple choice) questions (Annexure I). The close ended questions were provided with 2-4 answer options and students were asked to tick the right option. The questionnaire was based on previous studies conducted on students regarding their awareness about herbal medicines and was suitably modified as per requirements of the present study. ${ }^{20,21}$ The questionnaire was validated by a pilot study on 30 students and colleagues to check the relevance, question length, clarity of questions and was modified as per the feedback obtained. All those who had participated in the pilot study were excluded from the study.

The questionnaire gathered information on age, sex, knowledge, awareness and usage of herbal medicines and about herb-drug interactions. The completed questionnaires were collected; and data obtained were analyzed and expressed as counts and percentages.

\section{RESULTS}

\section{Table 1: Demographic characteristics of study participants.}

\begin{tabular}{|ll|}
\hline Characteristics & $\mathbf{n}=$ No. of Students (Percentage) \\
\hline Gender & \\
Male & $107(37.41 \%)$ \\
Female & $179(62.59 \%)$ \\
\hline Age (years) & \\
$19-20$ & $85(29.72 \%)$ \\
$21-22$ & $152(53.15 \%)$ \\
$23-24$ & $40(13.99 \%)$ \\
$>24$ & $9(3.15 \%)$ \\
\hline
\end{tabular}

A total of 286 students completed the questionnaire, which included 100 students from $2^{\text {nd }}$ year, 96 from $3^{\text {rd }}$ year and 90 from final year. Female students $(62.59 \%)$ were much more than male students. Average age of the participating students was 21.41 years; maximum number 
of students were in the age range of 21-22 years (53.15\%, $\mathrm{n}=152$ ) (Table 1). Average time taken by the participants to complete the questionnaire was 12 minutes (range from 11 to 15 minutes).

Majority (95.45\%; $\mathrm{n}=273)$ of the students were aware that herbs can be used as medicines. $46.85 \% \quad(n=134)$ were of the opinion that herbal medicines are risk free, whereas $42.66 \%$ felt that herbal medicines are not riskfree (Figure 1). A total of 54 herbs were known to the students. They were most familiar with tulsi $(48.6 \%$, $\mathrm{n}=139)$, followed by neem $(31.47 \%, \mathrm{n}=90)$, turmeric $(17.13 \%, \mathrm{n}=49)$, aloe $(16.78 \%, \mathrm{n}=48)$, ashwagandha $(8.39 \%, \mathrm{n}=24)$ and ginger $(5.24 \%, \mathrm{n}=15)$. Some other herbs that few students were also aware of include amla, mulethi, mint, ginkgo, hing, asparagus, fennel, and shilajeet.

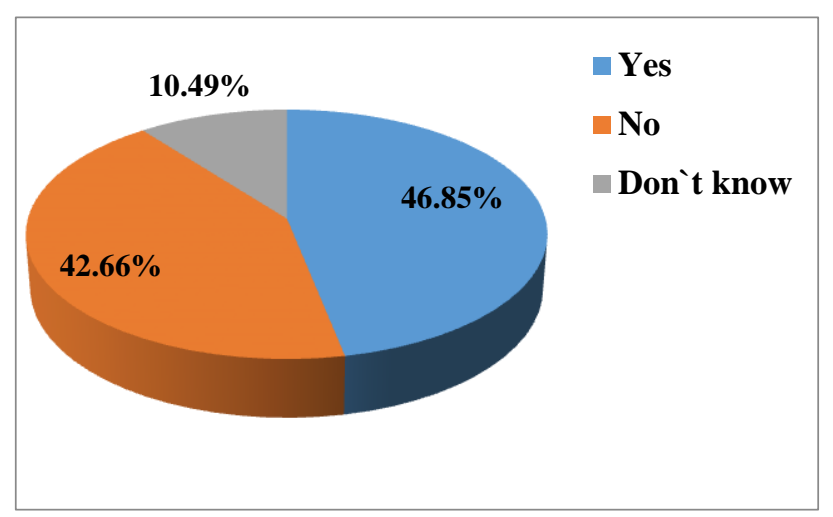

\section{Figure 1: Percentage of students who feel herbal medicines are risk free.}

Media (54.2\%) was the most common source of information for students regarding herbal medicines, followed by information from elderly (45.45\%) family member, and very rarely physicians. Many students gave more than one reply to this question and a total of 344 choices were ticked. From among the media, television $(43.23 \%)$ and internet $(40 \%)$ were the most common sources of information (Table 2).

$45.45 \%$ (130) students had used herbal medicine personally, and $40 \%$ were satisfied with the treatment (Table 2). The preferred choice of treatment from among herbal medicines and allopathic medicines was allopathic medicines $(75.17 \%$; $\mathrm{n}=215)$, in comparison to the herbal medicines $(24.82 \%, \mathrm{n}=71)$. Although 71 favoured herbal medicines, 150 students responded to the question regarding the reason for preference of herbal products: most $(64.67 \%)$ answered that herbal products are natural, followed by that herbal products are risk free $(24 \%)$, for general well-being $(6 \%)$, and family tradition $(5.33 \%)$.

Although only 134 students said that herbs are risk free, however all students responded to the question regarding the cause of adverse outcomes of herbs. 81 (28.32\%) students responded that adverse outcomes of the herbs could be due to adulteration, 18 mentioned inter-batch variability, 12 due to storage related issues, and majority $(61.54 \%, \mathrm{n}=175)$ of the students said that herbs can cause adverse reactions due to all these three reasons, i.e. interbatch variability, storage related issues and adulteration.

\section{Table 2: Personal usage and sources of information of herbal medicine.}

\begin{tabular}{|c|c|c|}
\hline Question & $\begin{array}{l}\text { Students } \\
\text { Response }\end{array}$ & $\begin{array}{l}\mathbf{n}=\text { No. of } \\
\text { Students } \\
\text { (Percentage) }\end{array}$ \\
\hline $\begin{array}{l}\text { Have you used any } \\
\text { herbal medicine } \\
\text { personally? }\end{array}$ & $\begin{array}{l}\text { Yes } \\
\text { No } \\
\text { Don't know }\end{array}$ & $\begin{array}{l}130(45.45 \%) \\
147(51.4 \%) \\
9(3.15 \%)\end{array}$ \\
\hline $\begin{array}{l}\text { If yes, were you } \\
\text { satisfied with the } \\
\text { treatment? }\end{array}$ & $\begin{array}{l}\text { Yes } \\
\text { No } \\
\text { Don't know }\end{array}$ & $\begin{array}{l}52(40.0 \%) \\
44(33.87 \%) \\
34(26.15 \%) \\
\end{array}$ \\
\hline $\begin{array}{l}\text { Source of } \\
\text { information } \\
\text { regarding herbal } \\
\text { medicines? }\end{array}$ & $\begin{array}{l}\text { Media } \\
\text { Physicians } \\
\text { Friends } \\
\text { Store displays } \\
\text { Elders }\end{array}$ & $\begin{array}{l}155(54.2 \%) \\
12(3.49 \%) \\
29(8.43 \%) \\
18(5.23 \%) \\
130(45.45 \%)\end{array}$ \\
\hline $\begin{array}{l}\text { If media, then } \\
\text { specify the specific } \\
\text { source? }\end{array}$ & $\begin{array}{l}\text { TV } \\
\text { Radio } \\
\text { Internet } \\
\text { Newspaper }\end{array}$ & $\begin{array}{l}67(43.23 \%) \\
5(3.23 \%) \\
62(40 \%) \\
21(13.55 \%)\end{array}$ \\
\hline
\end{tabular}

A greater proportion $(55.59 \%, \mathrm{n}=159)$ were not aware of the fact that herbs can interact with drugs, and only $44.41 \%(n=127)$ students had the knowledge that herbs can cause herb-drug interactions. (Figure 2) Although majority $(84.96 \%)$ of the students felt that history regarding use of herbal medicines should be taken, only $23.07 \%$ students always informed the physician about the use of herbal medicines and most $(44.75 \%)$ never informed their doctor about the use of herbal products. The most common reason for not informing the doctor was that they never felt the need to inform the doctor (43\%), followed by the reply that the doctor doesn't ask (22.5\%), doctor might not be interested to know (18\%), and that the herbal medicines are safe $(16.5 \%)$. Only 13 students could name any herb-drug interactions, of which only four were correct.

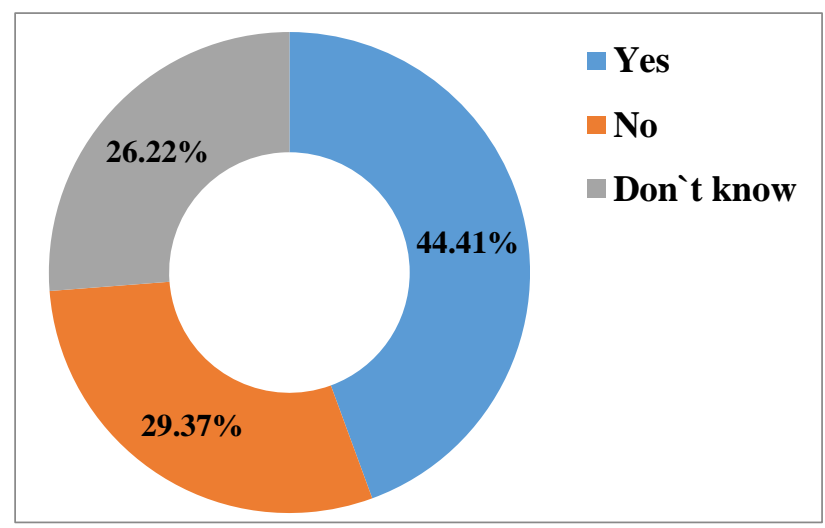

Figure 2: Percentage of students who feel herbs can interact with drugs. 
The most common source of scientific information on herbal product that students would refer to was internet $(55.59 \%, \mathrm{n}=159)$, followed by medical journals $(16.78 \%$, $\mathrm{n}=48)$, herbal pharmacopoeias $(14.68 \%, \mathrm{n}=42)$, and books $(12.94 \%, \mathrm{n}=37)$.

$26.22 \%(n=75)$ students replied that United States Food and Drug administration (FDA) controls herbal medicines, $28.67 \% \quad(n=82)$ replied that FDA does not control herbal medicines, and $45.10 \%(n=129)$ had no knowledge whether or not FDA controls herbal medicines. Also, most $(62.24 \%, \mathrm{n}=178)$ were not aware of the status whether or not Drug Controller General of India (DCGI) is also the regulatory authority for herbal medicines in India, and 45 were of the opinion that DCGI regulates herbal medicines in India.

\section{DISCUSSION}

The use of herbal drugs by large percentage of population may lead to lot of herb-drug interactions, the cause of which may go unnoticed in a number of patients due to the lack of knowledge of HDIs among physicians. In this study, the medical students were found to be quiet deficient in the knowledge regarding herbal medicines and the HDIs, similar to that seen in earlier studies. ${ }^{17,22,23}$

Most $(95.45 \%)$ of the students were aware that herbs can be used as medicines, quiet similar to earlier study by Sekhri K et al on dental students. In our study $46.85 \%$ were of the opinion that herbal medicines are risk-free, in contrast to the study by Sekhri $\mathrm{K}$ et al, where $82.5 \%$ considered herbal medicines as natural and safe with no side effects. ${ }^{22}$ This difference may be because only $2^{\text {nd }}$ year dental students were included in their study, in comparison to our study where in addition to the $2^{\text {nd }}$ year medical student, $3^{\text {rd }}$ and $4^{\text {th }}$ year medical students were included who have relatively more exposure to patients. The general concept that herbal drugs are risk free is misleading, as herbal drugs are known to cause adverse effects ranging from mild to serious, life-threatening conditions, and even death. ${ }^{11,24,25}$

Also, it should be mentioned here that all the adverse effects due to herbs may not be due to the active ingredient (medicine), but may also be due to the impurities like pollen, spores, other allergens present due to variation in the source of herbal product, contamination, adulteration, and mislabelling. This is because the quality and purity of manufacturing of herbal medicines by many companies is not standardized, and can vary between different manufacturers of the same product, or even between different batches of the same product from the same manufacturer. Improper storage may also lead to instability of active ingredient. ${ }^{10,26}$ In our study, all three - inter-batch variability, storage related issues and adulteration were considered the most common causes of adverse outcomes of herbs.
In our study, the students were most familiar with herbal medicines tulsi $(48.6 \%)$, neem $(31.47 \%)$, turmeric $(17.13 \%)$, aloe $(16.78 \%)$, ashwagandha (8.39) and ginger $(5.24 \%) .60 \%-70 \%$ of the students in an earlier study were familiar with turmeric, neem, aloe vera, garlic and clove; probably because of close ended questions in comparison to open-ended questions in our study. ${ }^{22}$ In another study by Ameade EP et al, students knew more about Neem, Pawpaw, moringa mainly for their use in malaria. The difference could probably be due to the geographical variation, and due to malaria being endemic in the region. ${ }^{23}$ Media (54.2\%), especially television and internet were the most common sources of information on herbal medicines, followed by elderly $(45.45 \%)$ family member. In most of the other studies, family members were the main source of information about herbal medicines, which may be non-scientific as the information is generally based on local beliefs. ${ }^{22,27}$

Most (55.6\%) were not aware of the fact that herbs can interact with drugs and can cause herb-drug interactions, similar to the findings in an earlier study. ${ }^{22}$ Only 4 students could correctly name any herb-drug interactions, which highlights their lack of knowledge regarding the topic. This is supported by the studies by $\mathrm{Xu} \mathrm{S}$ et al., Sekhri et al. where the medical residents and students felt that they had very little exposure to the topic of herbal medicines in their formal education. ${ }^{19,22}$

$45.45 \%$ students had used herbal medicine for personal use, slightly lesser than in the study by Sekhri $\mathrm{K}$ et al $(60.77 \%)$ and Ameade EP et al $(54.7 \%))^{22,23}$ Thus, there is high level of use of herbal medicines even among medical students. In our study, $40 \%$ of users were satisfied with the treatment in contrast to the study in Ghana where $77.5 \%$ were satisfied. ${ }^{23}$ Greater proportion of students $(75.17 \%)$ preferred allopathic medicines in comparison to herbal medicines in our study. The main reasons selected for preference of herbal products were that herbal products are natural and risk free.

Majority of students were not aware of regulatory control of herbal medicines by FDA or DCGI. Literature search could not reveal similar data as previous studies have not questioned students regarding the regulatory control. Herbal medicines are considered as dietary supplements by the Food and Drug Administration (FDA). Dietary supplements are regulated by FDA, but not as rigorously as allopathic medications. Thus, manufacturers do not have to go through FDA approval prior to bringing an herbal medicine to the market. The central drug controlling authority in India, Drug controller general of India (DCGI) has only allopathic drug approvals under its purview. The herbal drugs in India are reviewed by the department of Ayush, and do not have a Central drug controlling authority. ${ }^{19,28-30}$ Non-centralized non-stringent control may lead to production of sub-standard herbal products by many companies. 
Most students would prefer internet $(55.59 \%)$ as their source of scientific information on herbal product. So, they should be taught to choose the authentic sources of information from the vast web of internet to prevent gathering of wrong information. 42 students answered herbal pharmacopoeias, which shows that they have some knowledge about source of information for herbal medicines, slightly better than another study which showed very poor knowledge of the herbal pharmacopoeia. ${ }^{23}$

Although majority $(84.96 \%)$ of the students felt that history regarding use of herbal medicines should be taken, they rarely informed the physician about their consumption of herbal medicines. Most common reasons were that they never felt the need to inform the doctor, and that the doctor never enquired about herbal drug usage. This poor doctor-patient communication regarding herbal products could be because the physicians are less confident due to their lack of knowledge on herbal medicines, as has been seen in various studies. ${ }^{17-19}$ In another study, majority of the students believed they will take history from patients of usage of herbal medicines when they start prescribing to patients. $^{23}$

With the increasing use of herbal medicines worldwide, the number of adverse effects and HDIs are also on the rise. To overcome these, the regulatory process of approval of herbal medicines, their manufacturing, storage, marketing and use should be standardized and made more stringent for the safety of the patients. There should be clear communication between doctors and patients to prevent any herb-drug interactions from happening. Education and training regarding the herbdrug interactions should be a part of the medical curriculum especially during the undergraduate pharmacology practical classes, as has been introduced in few medical colleges in India, so that they have good knowledge and awareness about the herb-drug interactions before they start prescribing drugs to the patients.

Limitations of the present study include participation of students from a single institute: multicentre study will be beneficial; also, involvement of physicians and interns who are prescribing drugs to the patients would have better impact on the study outcome.

\section{CONCLUSION}

The students' had low level of knowledge and awareness about herbal medicines and about herb-drug interactions. There is a need to educate and train the medical students about the adverse outcomes of herbal medicines and the knowledge about herb-drug interactions should be a part of the medical curriculum. Students should also be sensitized to enquire about the use of herbal medicines by patients as a part of clinical history taking.

\section{ACKNOWLEDGEMENTS}

We thank all students of Gian Sagar medical college and hospital who contributed to the completion of this study.

Funding: No funding sources

Conflict of interest: None declared

Ethical approval: The study was approved by the Institutional Ethics Committee

\section{REFERENCES}

1. General guidelines for methodologies on research and evaluation of traditional medicine. WHO/EDM/TRM/2000.1 Available at: http://www.who.int/medicines/areas/traditional/defini tions/en/

2. Robinson MM, Zhang X. The World Medicines Situation 2011- Traditional Medicines: Global Situation, Issues and Challenges. WHO: Geneva, Switzerland. 2011:1-14.

3. Vaidya AD, Devasagayam TP. Current status of Herbal. Drugs in India: An Overview. J. Clin. Biochem. Nutr. 2007;41(1):1-11.

4. Hussain MS. Patient counseling about herbal-drug interactions. Hussain Afr J Tradit Complement Altern Med. 2011;8(S):152-63.

5. Heinrich $\mathrm{M}$, Booker A. Herbal medicines in the United Kingdom. In: Medicinal and Aromatic Plants of the World. Paris: EOLSS; 2012.

6. Izzo AA, Ernst E. Interactions between herbal medicines and prescribed drugs: an updated systematic review. Drugs. 2009;69:1777-98.

7. Déciga-Campos M, Rivero-Cruz I, Arriaga-Alba M, Castañeda-Corral G, Angeles-López GE, Navarrete A et al. Acute toxicity and mutagenic activity of Mexican plants used in traditional medicine. J. Ethno Pharmacol. 2007;110:334-42.

8. Patel M, Bessong P, Liu H. Traditional medicines, HIV, and related infections: workshop 2C. Adv. Dent. Res. 2011;23:159-64.

9. Fugh-Berman A. Herb-drug interactions. Lancet 2000;355:134-8.

10. Gohil KJ, Patel JA. Herb-drug interactions: A review and study based on assessment of clinical case reports in literature. Ind J Pharmacol. 2007;39:12939.

11. Posadzki P, Watson L, Ernst E. Herb-drug interactions: an overview of systematic reviews. British Journal of Clinical Pharmacology. 2013;75(3):603-18.

12. Chao MT, Wade C, Kronenberg F. Disclosure of complementary and alternative medicine to conventional medical providers: variation by race/ethnicity and type of CAM. J Natl Med Assoc. 2008;100:1341-9.

13. Howell L, Kochhar K, Saywell R, Zollinger T, Koehler J, Mandzuk C, et al. Use of herbal remedies by Hispanic patients: do they inform their physician? J Am Board Fam Med. 2006;19:566-78. 
14. Gardiner P, Graham RE, Legedza AT, Eisenberg DM, Phillips RS. Factors associated with dietary supplement use among prescription medication users. Arch Intern Med. 2006;166:1968-74.

15. Kennedy J, Wang CC, Wu CH. Patient Disclosure about Herb and Supplement Use among Adults in the US. Evid Based Complement Alternat Med. 2008;5:451-6.

16. Klepser TB, Doucette WR, Horton MR. Assessment of patients' perceptions and beliefs regarding herbal therapies. Pharmacotherapy. 2000;20:83-7.

17. Clement YN, Williams AF, Khan K, Bernard T, Bhola S, Fortuné M, et al. A gap between acceptance and knowledge of herbal remedies by physicians: the need for educational intervention. BMC Complement Altern Med. 2005;5:20.

18. Fakeye TO, Onyemadu O. Evaluation of knowledge base of hospital pharmacists and physicians on herbal medicines in Southwestern Nigeria. Pharm. Pract. 2008;6:88-92.

19. Xu S, Levine M. Medical residents' and students' attitudes towards herbal medicines: a pilot study. Can J Clin Pharmacol. 2008;5:14.

20. Gardiner P, Graham R, Legedza AT, Ahn AC, Eisenberg DM, Phillips RS. Factors associated with herbal therapy use by adults in the United States. Altern Ther Health Med. 2007;13:22-9.

21. Zimmerman C, Kandiah J. A pilot study to assess students' perceptions, familiarity, and knowledge in the use of complementary and alternative herbal supplements in health promotion. Altern Ther Health Med. 2012;18:28-33.

22. Sekhri K, Bhanwra S, Nandha R. Herbal products: a survey of students' perception and knowledge about their medicinal use. Int $\mathrm{J}$ Basic Clin Pharmacol. 2013;2:71-6.
23. Ameade EP, Amalba A, Helegbe GK, Mohammed BS. Herbal medicine: a survey on the knowledge and attitude of medical students in Tamale, Ghana. Peak Journal of Medicinal Plant Research. 2015;3(1):1-8.

24. Vanherweghem JL, Degaute JP. The policy of admission to the education in medicine and dentistry in the French-speaking community of Belgium. Acta Clin. Belg. 1998;53:2-3.

25. Ernst E. Toxic heavy metals and undeclared drugs in Asian herbal medicines. Trends Pharmacol Sci. 2002;23:136-9.

26. Liang Y, Xie P, Chan K. Quality control of herbal medicines. J Chromatogr. 2004;812:53-70.

27. Perkin JE, Wilson WJ, Schuster K, Rodriguez J, Allen-Chabot A. Prevalence of nonvitamin, nonmineral supplement usage among university students. J Am Diet Assoc. 2002;102:412-4.

28. Sahoo N, Manchikanti P. Herbal Drug Regulation and Commercialization: An Indian Industry Perspective. J Altern Complement Med. 2013;19(12):957-63.

29. Bent S. Herbal Medicine in the United States: Review of Efficacy, Safety, and Regulation. J Gen Intern Med 2008;23(6):854-9.

30. Rivera JO, Loya AM, Ceballos R. Use of Herbal Medicines and Implications for Conventional Drug Therapy Medical Sciences. Altern Integ Med 2013;2:130.

Cite this article as: Boparai JK, Singh A, Gupta AK, Matreja PS, Khanna PML, Gupta V, et al. A study to determine the knowledge and level of awareness of medical undergraduates about herbal medicines and herb-drug interactions. Int $\mathrm{J}$ Basic Clin Pharmacol 2017;6:17-24. 


\section{Annexure I}

Age (yrs.)/Sex: Time taken to fill:

1. Herbs can be used as medicines:

a) Yes b) No c) Don`t know

2. Herbal medicines are risk free:

a) Yes b) No c) Don`t know

3. Name any 3 herbs and their use:

4. Herbs can interact with drugs:
a) Yes b) No c) Don`t know

5. Adverse outcomes of herbs can be due to: (circle one)

a) Inter-Batch variability b) Adulteration

c) Storage d) All

6. FDA controls herbal medicines:
a) Yes b) No c) Don`t know

7. Source of information regarding herbal medicines:

a) Media (TV, radio, internet, newspaper) b) Physicians

c) Friends d) Store displays e) Elders

7A. If the answer is media, then specify the source:

a) TV b) Radio c) Internet d) Newspaper

8. Have you used any herbal medicine personally?

a) Yes b) No c) Don`t know

8A. If yes, were you satisfied with the treatment?

a) Yes b) No c) Don`t know

9. What is your preferred treatment?

a) Herbal medicine b) Allopathic medicine

9A. If your preference is herbal products, tick the reasons:

a) Herbal products are natural b) Herbal products are risk free

c) Herbal products are for general well-being d) Family tradition

10. How often do you inform your doctor about the use of herbal products? 
a) Always b) Never c) Rarely d) Frequently

11. What is your reason for not informing the doctor?

a) I feel herbal medicines are safe b) Doctor doesn't ask

c) I feel Doctor might not be interested to know d) Never felt the need to inform

12. Do you feel history regarding herbal medicines should be taken?

a) Yes b) No

13. Can you name any herb-drug interactions?

14. What would be your source of scientific information on herbal products? (Circle one)

a) Medical journals b) Herbal pharmacopoeias

c) Books d) Internet

15. DCGI is the regulatory authority for allopathic medicine in India; do you think herbal medicines are also regulated by the same authority?

a) Yes b) No c) Don`t know 